\title{
PERAN PSYCHOLOGICAL CAPITAL DAN PERSON - ORGANIZATION FIT TERHADAP KESIAPAN I-GENERATIONS UNTUK BERUBAH
}

\author{
Oleh : \\ Yanuar Surya Putra \\ Dosen Tetap STIE AMA Salatiga
}

\begin{abstract}
Organizational change is a major issue affecting all organizations in various industry and government sectors, it can be said that change has become the norm for organizations to maintain the existence and success of the organization. The purpose of this study This study will examine the effect of psychological capital and Person - Organization Fit on individual readiness to change at college graduates in Salatiga who belong to iGeneration group. Generation Z or iGeneration, is a new generation starting their career, so the behavior of this generation in the world of work has not begun to get attention, expectations expected from employees of the $Z$ generation are different from generation $Y$ and generation $X$. This study uses college graduates in Salatiga as sample, and sampling method used is purposive sampling. The research instrument used is a questionnaire that was first tested with validity and reliability test. The number of samples used is 170 people. Data analysis was done by Multiple Regression Analysis with equation path analysis. After the validity and reliability test of the research instrument, the profile of the respondents can be summarized as follows: number of male respondents (63\%), age between 21-22 years (74\%), duration 1 - 10 months (85\%). The results of this study can be summarized as follows: (1) The two variables Psychological Capital and Person - Fit Fit have a positive and significant impact on the desire igenerations to change. (2) Effect of Psychological Capital (31.4\%) on the readiness of igenerations to change more high than the influence of Person - Organizations Fit (28.3\%). Organizational and managerial support such as effective communication on change, training, coaching and counseling can be regarded as initiatives that can increase individual readiness to change. Employee involvement in the change management process is also believed to enhance meaning and self-confidence and thereby increase individual readiness to change.
\end{abstract}

Keywords: Psychological Capital, Person - Organization Fit, Readiness to Change, iGenerations.

\section{PENDAHULUAN}

Perubahan Organisasi menjadi isu utama yang mempengaruhi semua organisasi dalam berbagai sektor industri dan pemerintahan, dapat dikatakan bahwa perubahan telah menjadi norma bagi organisasi untuk menjaga eksistensi dan keberhasilan organisasi. Organisasi industri maupun pemerintahan secara konstan harus selalu mengupayakan keselarasan antara kegiatan operasional organisasi dengan lingkungan 
yang terus berubah. Namun demikian, tidak semua proses perubahan organisasi menghasilkan kesuksesan. Menurut Fachruddin \& Mangundjaya (2012) kegagalan dalam mengelola perubahan secara efektif akan menghasilkan sumber daya yang terbuang, kinerja organisasi yang buruk dan menurunnya moral karyawan.

Mengelola perubahan organisasi sama halnya dengan mengelola aspek manusia didalam organisasi, sehingga untuk dapat mendukung perubahan organisasi, individu dalam organisasi harus memiliki kesiapan untuk berubah (Armenakis et al., 1993; Armenakis, Haris, \& Field, 1999). Lebih lanjut Pelletiere (2006) juga mendukung pendapat tersebut dengan menjelaskan bahwa salah satu alasan mengapa proses perubahan organisasi seringkali mengalami kegagalan adalah karena ketidaksiapan untuk berubah. Oleh karena itu penting bagi manajer dan pimpinan organisasi untuk melakukan penilaian terhadap kesiapan individu maupun organisasi untuk berubah, dan juga perlu bagi manajer dan pimpinan organisasi untuk mengetahui faktor - faktor yang mempengaruhi kesiapan perubahan individu dan organisasi (Madsen, 2005).

Beberapa penelitian telah dilakukan sebelumnya menunjukkan ada banyak faktor yang mempengaruhi kesiapan untuk berubah. Faktor-faktor tersebut dikelompokkan menjadi faktor individu dan faktor organisasional. Eby et al. (2000) menyatakan bahwa perilaku dan preferensi individu, kelompok kerja, dan perilaku kerja memiliki pengaruh terhadap kesiapan untuk berubah. Sementara itu Hanpachern, Morgan, and Griego (2005) menemukan bahwa pengetahuan dan skil karyawan, budaya organisasi, hubungan interpersonal, hubungan karyawan dengan atasan berpengaruh terhadap kesiapan individu untuk berubah. Dari hasil penelitian tersebut faktor individual yang belum mendapat perhatian dalam penelitian tentang manajemen perubahan khususnya tentang keinginan individu untuk berubah adalah faktor psikologis. Padahal jika ditelusur faktor psikologis adalah faktor utama yang muncul dalam literatur awal manajemen perubahan dan faktor psikologis adalah faktor yang menyebabkan individu mau berubah atau tidak (Lewin; 1948, Schein; 1988; Cummings \& Huse; 1989).

Pemahaman terhadap Person-Organization Fit (P-O fit) dapat membantu perusahaan untuk memilih para karyawan dengan nilai dan keyakinan yang sesuai dengan organisasi dan membentuk pengalaman-pengalaman yang dapat memperkuat kesesuaian tersebut. Person organization Fit (P-O fit) didefinisikan sebagai 
kesesuaian antara nilai - nilai organisasi dengan niali-nilai individu (Kristof, 1996). Para praktisi dan peneliti berpendapat bahwa P-O fit adalah kunci utama untuk memelihara dan mempertahankan komitmen karyawan yang sangat diperlukan dalam lingkungan bisnis yang kompetitif (Bowen, Ledrof \& Nathan, 1991; Kristof, 1996).

Kesiapan individu untuk berubah didalam organisasi juga tergantung oleh karakteristik karyawan dalam organisasi tersebut, sehingga dapat dipastikan bahwa akan ada keragaman karakteristik karyawan dalam sebuah organisasi, termasuk keragaman dalam pengelompokan generasi. Mannheim (1952) mengungkapkan bahwa generasi adalah suatu konstruksi sosial dimana didalamnya terdapat sekelompok orang yang memiliki kesamaan umur dan pengalaman historis yang sama. Definisi tersebut secara spesifik juga dikembangkan oleh Ryder (1965) yang mengatakan bahwa generasi adalah agregat dari sekelompok individu yang mengalami peristiwa - peristiwa yang sama dalam kurun waktu yang sama pula. Perkembangan konsep generasi yang banyak dipakai sebagai referensi dalam penelitian adalah pendapat dari Kupperschmidt (2000) yang mendefinisikan generasi sebagai sekelompok individu yang diidentifikasi dari kesamaan tahun kelahiran, umur, dan peristiwa - peristiwa yang berpengaruh terhadap fase pertumbuhan mereka. Dalam konteks keragaman angkatan kerja perbedaan generasi juga menjadi salah satu isu mendasar selain gender, ras, agama,budaya dan afiliasi politik, setiap generasi akan memiliki ekspektasi, aspirasi, nilai, dan perilaku yang berbeda dalam lingkungan kerja (Crampton \& Hodge 2007).

Pengelompokan perbedaan generasi memang sulit untuk dapat dibatasi secara spesifik, karena adanya perbedaan wilayah dan peristiwa yang dialami oleh sekelompok individu tersebut, meskipun mereka berada pada interval umur yang sama, sehingga dalam literatur tentang perbedaan generasi digunakan kriteria yang umum dan bisa diterima secara luas diberbagai wilayah, dalam hal ini kriteria yang dipakai adalah tahun kelahiran dan peristiwa - peristiwa yang terjadi secara global. Salah satu pengelompokan generasi dengan kriteria tersebut menurut Andrea, Gabriela dan Timea (2016) adalah sebagai berikut : 
Tabel 1

Pengelompokan Generasi

\begin{tabular}{cl}
\hline Tahun Kelahiran & Generasi \\
\hline $\mathbf{1 9 2 5}-\mathbf{1 9 4 6}$ & Veteran generation \\
$\mathbf{1 9 4 6}-\mathbf{1 9 6 0}$ & Baby boomers \\
$\mathbf{1 9 6 0}-\mathbf{1 9 8 0}$ & X generation \\
$\mathbf{1 9 8 0}-\mathbf{1 9 9 5}$ & Y generation \\
$\mathbf{1 9 9 5}-\mathbf{2 0 1 0}$ & Z generation \\
$\mathbf{2 0 1 0}+$ & Alfa generation \\
\hline
\end{tabular}

Sumber: Andrea, Gabriela dan Timea (2016)

Di Indonesia sendiri Generasi Y adalah generasi yang saat ini mendominasi pasar tenaga kerja, data BPS tahun 2015 menunjukkan bahwa penduduk Indonesia baik pria maupun wanita yang terbanyak adalah pada kelompok umur 15 - 64 tahun, dan komposisi terbesar sekitar 100 juta dari kelompok umur tersebut masuk dalam generasi Y, dan dalam 5 tahun kedepan dominasi tersebut akan mulai digantikan oleh generasi $\mathrm{Z}$ atau iGeneration.

Generasi Z, menurut Andrea (2016) generasi Z disebut juga iGeneration atau generasi internet. Generasi $\mathrm{Z}$ memiliki kesamaan dengan generasi $\mathrm{Y}$, tapi generasi $\mathrm{Z}$ mampu mengaplikasikan semua kegiatan dalam satu waktu (multi tasking). Generasi $\mathrm{Z}$ atau iGeneration, adalah generasi yang baru memulai karir mereka, sehingga perilaku generasi ini dalam dunia kerja belum mulai mendapat perhatian, ekspektasi yang diharapkan dari karyawan dari generasi $\mathrm{Z}$ berbeda dari generasi $\mathrm{Y}$ dan generasi X (Ozkan \& Solmaz, 2015), hal tersebut akan menjadi tantangan bagi organisasi (Singh, 2014). Penelitian ini akan meneliti pengaruh dari psychological capital dan Person - Organization Fit terhadap kesiapan individu untuk berubah pada lulusan perguruan tinggi di Salatiga yang masuk dalam kelompok iGeneration.

\section{LANDASAN TEORI DAN PENGEMBANGAN HIPOTESIS}

\section{Kesiapan Individu untuk Berubah (Individual Readiness to Change)}

Armenakis \& Harris (2002); Bernerth (2004) menyatakan bahwa kesiapan individu untuk berubah terdiri dari keyakinan dan sikap terhadap sebuah inisiatif perubahanan atau dengan kata lain kesiapan individu untuk berubah adalah kumpulan pemikiran menuju inisiatif perubahan, sementara Holt (2007) mengatakan bahwa kesiapan individu untuk berubah adalah sikap komprehensif yang secara simultan dipengaruhi oleh konten (apa yang telah diubah), proses (bagaimana akan berubah), 
konteks (dalam situasi apa perubahan itu dilakukan) dan karakteristik individu yang terlibat dalam perubahan. Menurut beberapa penelitian sebelumnya (Armenakis et al., 1993; Madsen, Miller, \& John, 2005; Hanpachern, Morgan \& Griego di Madsen, et al., 2005; Weber \& Weber di Fachruddin \& Mangundjaya, 2012; dan Holt et al. 2007), ada banyak faktor yang dapat mempengaruhi kesiapan individu untuk berubah.

Faktor tersebut dapat dikelompokkan menjadi individu dan organisasi. Armenakis dkk. (1993) berpendapat bahwa pesan perubahan harus membahas tiga faktor penting: kebutuhan akan perubahan yang nyata, rasa kemampuan seseorang untuk mencapai perubahan (self-efficacy), dan kesempatan untuk berpartisipasi dalam proses perubahan. Eby dkk. (2000) mengusulkan bahwa sikap dan preferensi individu, kelompok kerja dan perilaku kerja, dan variabel kontekstual akan berpengaruh pada kesiapan untuk perubahan. Pada tingkat kelompok kerja, partisipasi yang dirasakan dalam tim dan kepercayaan terhadap rekan kerja meningkatkan kesiapan perubahan. Akhirnya, individu yang menganggap bahwa kebijakan organisasi yang fleksibel akan memiliki dukungan yang lebih tinggi untuk perubahan dalam organisasi.

Lebih lanjut Madsen, Miller, \& John (2005) menemukan bahwa komitmen, identifikasi dalam organisasi, loyalitas dan keterlibatan karyawan memiliki korelasi positif dengan tingkat kesiapan individu untuk berubah. Devos et al.(2008) menemukan bahwa faktor demografi seperti pendidikan dan posisi kerja memiliki korelasi positif dengan kesiapan individu untuk berubah. Karyawan dengan latar belakang pendidikan tinggi serta posisi kerja memiliki tingkat kesiapan individu untuk berubah yang lebih tinggi (Fachruddin \& Mangundjaya, 2012). Penelitian Huy (2012) menemukan beberapa faktor lain yang mempengaruhi kesiapan individu untuk berubah. Faktor-faktor ini termasuk kepercayaan terhadap perubahan dukungan dan lingkungan organisasi yang baik. Sementara itu, Hanpachern, Morgan, dan Griego di Madsen et al.(2005) menemukan pengetahuan dan keterampilan karyawan, budaya organisasi, hubungan interpersonal di tempat kerja, serta hubungan antara karyawan dan manajemen atau pemimpin juga secara positif mempengaruhi kesiapan individu untuk berubah.

Selanjutnya, penelitian oleh Fachruddin \& Mangundjaya (2012) juga menemukan bahwa psychological capital sebagai bagian dari aspek individu secara positif mempengaruhi kesiapan individu untuk berubah. 
Sebagian besar literatur selanjutnya nampaknya mendukung kesiapan individu untuk melakukan perubahan organisasi tampaknya merupakan anteseden perubahan yang berhasil. Hanpachren (1997) mengembangkan instrumen untuk mengukur kesiapan individu untuk perubahan. Instrumen terdiri dari tiga dimensi sebagai berikut; (1) menolak; (2) Berpartisipasi; dan (3) Mempromosikan. Resisting atau menolak adalah sikap negatif individu menuju perubahan Berpartisipasi adalah partisipasi individu dalam proses perubahan. Mempromosikan mengacu pada seberapa jauh seseorang ingin menerapkan proses perubahan. Hipotesis penelitian yang dirumuskan sebagai berikut :

\section{H1: Terdapat pengaruh yang signifikan Psychological Capital dan P-O Fit terhadap} kesiapan igeneration untuk berubah.

\section{Psychological Capital}

Modal psikologis merupakan perkembangan psikologis positif individu yang itu terdiri dari (1) self-efficacy; (2) optimisme; (3) harapan; dan (4) ketahanan (Luthans, Youssef, \& Avolio, 2007). Sumber psikologis positif yang menjadi inti dari modal psikologis pada dasarnya berada pada aras kognitif individu. Misalnya, harapan didefinisikan sebagai arah menuju sasaran atau jalan menuju sasaran untuk mencapai keberhasilan (Snyder, Irving \& Anderson, 1991).

Self-efficacy didefinisikan sebagai kepercayaan seseorang tentang kemampuannya untuk memobilisasi motivasi, sumber daya kognitif atau tindakan yang dibutuhkan untuk berhasil melaksanakan tugas tertentu dalam konteks tertentu (Stajkovic \& Luthans, 1998). Optimisme didefinisikan sebagai atribusi yang dibuat dan cara yang digunakan untuk menanggapi kejadian (Selingman, 1998). Hal ini berorientasi pada evaluasi kejadian masa lalu atau yang telah terjadi, tidak hanya dikaitkan dengan masa depan. Seorang optimis adalah orang yang mengaitkan hasil suatu kejadian secara positif dan stabil, sedangkan kejadian atau hasil yang negative dianggap sebagai peristiwa eksternal yang mungkin juga tak terhindarkan. Selanjutnya ketahanan didefinisikan sebagai kemampuan seseorang untuk "bangkit kembali" atau "rebound" saat menghadapi kesulitan (Block \& Kremen, 1996; Masten et al., 1985). Hipotesis penelitian yang dirumuskan sebagai berikut : 
H2: Terdapat pengaruh yang signifikan Psychological Capital terhadap kesiapan igeneration untuk berubah.

\section{Person-Organization Fit}

Person organization Fit (P-O fit) secara umum didefinisikan sebagai kesesuaian antara nilai-nilai organisasi dengan nilai-nilai individu (Kristof, 1996). Sementara Donald dan Pandey (2007) mendefinisikan person-organization fit adalah adanya kesesuaian antara individu dengan organisasi, ketika: ada kesungguhan untuk memenuhi kebutuhan pihak lain, atau mereka memiliki karakteristik dasar yang serupa. Dalam melakukan perekrutan karyawan, perusahaan sering menggunakan pendekatan kesesuaian antara individu dengan pekerjaan yang ditawarkan (PersonJob Fit). Kristof (1996) berpendapat bahwa pendekatan person job fit ini kurang baik dalam proses seleksi karyawan, mereka berpendapat bahwa efektivitas organisasi tidak hanya didukung oleh kesuksesan tugas pekerjaan karyawan saja tetapi perlu memperhatikan perilaku karyawan secara luas. Beberapa peneliti berpendapat bahwa individu dan organisasi saling tertarik manakala terdapat kesesuaian antara satu dengan yang lain, hal ini sangat berpengaruh terhadap organisasi dalam merekrut karyawan dan juga sikap karyawan untuk memilih pekerjaan tersebut. Beberapa bukti empiris mendukung pernyataan ini (Chatman, 1989; O’ Reilly, Chatman \& Caldwell, 1991).

Menurut Kristof (1996), Person-Organization Fit dapat diartikan dalam empat konsep yaitu : (1) kesesuaian nilai (value congruence), adalah kesesuaian antara nilai instrinsik individu dengan organisasi (Chatman, 1989; Judge \& Bretz, 1992); (2) kesesuaian tujuan (goal congruence), adalah kesesuaian antara tujuan individu dengan organisasi dalam hal ini adalah pemimpin dan rekan sekerja; (3) pemenuhan kebutuhan karyawan (employee need fulfillment) adalah kesesuaian antara kebutuhankebutuhan karyawan dan kekuatan yang terdapat dalam lingkungan kerja dengan sistem dan struktur organisasi (Cable \& Judge, 1994; Turban \& Keon,1994); (4) kesesuaian karakteristik kultur-kepribadian (culture personality congruence) adalah kesesuaian antara kepribadian (non nilai) dari setiap individu dan iklim atau kultur organisasi (Bowen, Ledrof \& Nathan, 1991). 
H3: Terdapat pengaruh yang signifikan Person Organization Fit terhadap kesiapan igeneration untuk berubah.

\section{METODE PENELITIAN}

Penelitian ini menggunakan lulusan perguruan tinggi di Salatiga sebagai sampel, dan metode sampling yang digunakan adalah metode purposive sampling digunakan untuk mendapatkan responden $(\mathrm{n}=170)$. Ada beberapa kriteria yang digunakan dalam pemilihan sampel, kriteria tersebut didasarkan pada individu/lulusan yang baru saja bekerja dengan karakteristik sebagai berikut: lulusan perguruan tinggi yang sudah bekerja sebagai karyawan/trainee yang masuk dalam kelompok igeneration atau generasi Z, telah bekerja untuk perusahaan sekurang - kurangnya 6 bulan, minimal telah lulus dari perguruan tinggi, dan usia antara 21-23 tahun. Data dikumpulkan melalui 3 jenis kuesioner sebagai berikut: untuk variabel kesiapan individu kesiapan individu untuk berubah diadaptasi dari Hanpachern (1997) yang terdiri dari 3 dimensi: (1) Menolak; (2) berpartisipasi; dan (3) mempromosikan; Variabel Psychological Capital diadaptasi dari Luthans, Youssef \& Avolio (2007) yang terdiri dari 4 dimensi: (1) self-efficacy; (2) optimisme; (3) harapan; Dan (4) ketahanan; dan variabel Person - Organization Fit diadaptasi dari Kristof (1996), yang terdiri dari 4 dimensi: ((1) kesesuaian nilai (value congruence), adalah kesesuaian antara nilai instrinsik individu dengan organisasi; (2) kesesuaian tujuan(goal congruence); (3) pemenuhan kebutuhan karyawan (employee need fulfillment); (4) kesesuaian karakteristik kultur-kepribadian (culture personality congruence). Instrumen penelitian yang digunakan adalah kuesioner yang terlebih dahulu diuji dengan uji validitas dan reliabilitas.

\section{ANALISIS DATA}

Analisis data dilakukan dengan Multiple Regression Analysis dengan model persamaan satu jalur. Setelah dilakukan uji validitas dan reliabilitas dari instrumen penelitian, maka profil dari responden dapat diringkas sebagai berikut: jumlah responden pria (63\%), usia antara 21 - 22 tahun (74\%), lama bekerja $1-10$ bulan $(85 \%)$. 


\section{HASIL ANALISIS DAN PEMBAHASAN}

Hasil penelitian yang menunjukkan pengaruh Psychological Capital dan P-O Fit secara simultan dapat dilihat dari tabel berikut ini:

Tabel 2

Hasil Persamaan Jalur Secara Simultan

\begin{tabular}{cccc}
\hline Variabel & R & R Square & Adjusted R $^{\mathbf{2}}$ \\
\hline PsyCap, P-O Fit \& IRFC & 0,517 & 0,267 & 0,258 \\
\hline
\end{tabular}

Sumber: data primer yang diolah, 2017

Nilai R Square dari tabel diatas adalah 0, 267. Angka tersebut menunjukkan bahwa pengaruh Psychological Capital dan P-O Fit secara simultan terhadap kesiapan igenerations untuk berubah sebesar 26,7\%, sedangkan sisanya sebesar 73,3\% dipengaruhi oleh faktor lain. Untuk mengetahui apakah model regresi diatas sudah benar atau salah maka dilakukan uji hipotesis dengan uji $\mathrm{F}$ sebagaimana terlihat dari tabel berikut ini:

Tabel 3

Uji Hipotesis Secara Simultan

\begin{tabular}{ccc}
\hline Variabel & F & Sig. \\
\hline PsyCap, P-O Fit \& IRFC & 30,425 & 0,000 \\
\hline Sumber: data primer yang diolah, 2017
\end{tabular}

Taraf signifikansi dari Uji $\mathrm{F}$ dari tabel diatas menunjukkan nilai yang lebih kecil dari 0,05 sehingga dapat disimpulkan bahwa model regresi sudah benar, dengan kata lain $\mathrm{H} 1$ yang menyatakan terdapat pengaruh yang signifikan Psychological Capital dan $P$-O Fit terhadap kesiapan igenerations untuk berubah diterima. Untuk melihat besarnya pengaruh variabel Psychological Capital dan $P-O$ Fit terhadap kesiapan igenerations untuk berubah maka digunakan Uji t, dengan melihat standardized coefficients di bawah ini: 
Tabel 4

Hasil Persamaan Jalur dan Uji Hipotesis Parsial

\begin{tabular}{lccc}
\hline Variabel & Std coef Beta & $\mathbf{t}$ & Sig. \\
\hline PsyCap & 0,314 & 4,120 & 0,000 \\
P-O Fit & 0,283 & 3,708 & 0,000 \\
\hline
\end{tabular}

Sumber: data primer yang diolah, 2017

Hasil uji $\mathrm{t}$ diatas menunjukkan bahwa besarnya pengaruh variabel Psychological Capital terhadap kesiapan igenerations untuk berubah adalah sebesar 0,314 atau $31,4 \%$ dan $\mathrm{H} 2$ yang menyatakan bahwa terdapat pengaruh yang signifikan Psychological Capital terhadap kesiapan igeneration untuk berubah dapat diterima. Sedangkan besarnya pengaruh variabel $P-O$ Fit secara parsial terhadap kesiapan igenerations untuk berubah adalah sebesar 0,283 atau 28,3\% dan $\mathrm{H} 3$ yang menyatakan bahwa terdapat pengaruh yang signifikan $\mathrm{P}-\mathrm{O}$ Fit terhadap kesiapan igeneration untuk berubah dapat diterima. Model persamaan jalur dari hasil analisis diatas adalah sebagai berikut:

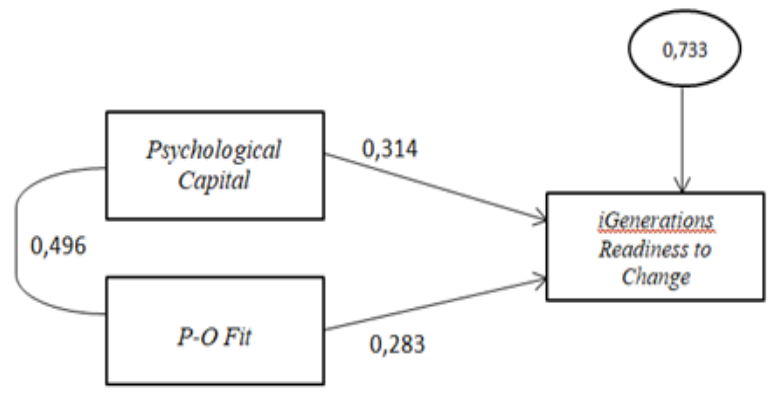

\section{Gambar 1 \\ Model Persamaan Jalur}

Dari gambar tersebut, hasil penelitian ini dapat disimpulkan sebagai berikut:

1. Kedua Psychological Capital dan Person - Organzation Fit memiliki pengaruh yang positif dan signifikan terhadap keinginan igenerations untuk berubah.

2. Pengaruh Psychological Capital $(31,4 \%)$ terhadap kesiapan igenerations untuk berubah lebih tinggi daripada pengaruh Person - Organizations Fit (28,3\%) 
Hasil penelitian menunjukkan bahwa aspek individu seperti Psychological Capital dan $P$-O Fit memiliki pengaruh positif terhadap kesiapan igenerations untuk berubah. Hasil penelitian juga menunjukkan bahwa pengaruh Psychological Capital lebih besar terhadap kesiapan individu untuk berubah dibandingkan dengan P-O Fit. Terlepas dari perbedaan budaya dan organisasi, temuan ini mendukung penelitian sebelumnya yang menemukan bahwa faktor individu secara khusus adalah Psychological Capital mendukung kesiapan individu untuk berubah. ( Lizar et.al, 2015; Haque, 2008; Cunningham, 2002; Rafferty \& Simmons, 2006; Lam, Cho \& Qu, 2007). Temuan dari penelitian ini juga mendukung Wenberg \& Banas (2000), yang menemukan kesiapan individu untuk berubah terkait dengan self-efficacy, self esteem, optimism, dan sense of control. Temuan penelitian ini juga mendukung Fachruddin \& Mangundjaya (2012), yang menyatakan bahwa Psychological Capital tersebut sebagai bagian dari aspek individu secara positif mempengaruhi kesiapan individu untuk berubah.

Generasi $\mathrm{Z}$ atau igenerations adalah orang-orang yang lahir antara tahun 1995 dan 2010, karakteristik untuk menggambarkan generasi ini meliputi: (1) menguasai teknologi dan mendigitalisasi semua aspek; (2) bertanggung jawab secara sosial, kultural, dan lingkungan; (4) pengguna sosial media tersbesar. Igenerations, yang akan bergabung dengan angkatan kerja, kebanyakan lahir di pertengahan tahun 1990an, mereka tumbuh dengan teknologi, world wide web, mp3 player, pesan singkat, handphone, PDA, YouTube, iPad, dan teknologi media lainnya. Generasi Z adalah individu yang percaya diri, bahagia, memiliki semangat bekerja dalam tim dan lebih tertarik pada kegiatan sosial dibanding generasi sebelumnya dan mampu memproses banyak informasi dengan cepat. Dapat dikatakan bahwa igenerations ini adalah generasi yang siap untuk berubah dan lebih mudah untuk beradaptasi dengan perubahan, bahkan mereka tidak menyukai kondisi yang statis dan penuh rutinitas, Jika dikaitkan dengan Psychological Capital maka igenerations memiliki self-efficacy, self esteem, optimism, dan sense of control yang tinggi.

Person - Organization Fit juga menjadi faktor yang mempengaruhi kesiapan igenerations untuk berubah. Generasi ini memegang nilai - nilai personal mereka dengan kuat. Individu dari generasi ini adalah karyawan yang inovatif dan kreatif, ingin memberi dampak pada masyarakat. Mereka ingin maju dan berkembang secara 
profesional, dan bersedia untuk magang dan belajar untuk mendapatkan pengalaman. Igenerations juga lebih tertarik untuk bekerja untuk perusahaan yang mereka minati, dan mungkin bersedia dibayar lebih sedikit selama mereka berminat bekerja di perusahaan tersebut. Untuk menarik tenaga kerja muda berbakat pada generasi ini, perusahaan harus menawarkan gaji dan tunjangan yang kompetitif; Jika tidak mereka akan mudah berpindah ke perusahaan lain yang dapat memenuhi permintaan mereka. Generasi ini juga memiliki harapan yang tinggi terhadap hubungan mereka dengan atasan mereka, Meskipun mereka ahli dalam dunia media sosial, pesan teks dan email, mereka lebih suka melakukan komunikasi dan tatap muka yang tulus dengan atasan mereka

\section{SIMPULAN DAN SARAN}

Psychological Capital dan Person - Organization Fit adalah faktor yang memiliki peran penting dalam perubahan organisasi. Kedua variabel tersebut memiliki pengaruh positif dalam menciptakan kesiapan individu khususnya igenerations untuk berubah. Berdasarkan temuan ini organisasi yang sedang ada didalam proses perubahan perlu memperhatikan hal ini: inisiatif untuk berubah harus menjangkau semua level, tidak hanya level organisasi, tetapi juga pada level individual dan level kelompok. Banyak organisasi menaruh sebagian besar usahanya untuk mengubah strategi organisasi, struktur, sistem dan prosedur organisasi namun mengabaikan perubahan individu dalam organisasi. Untuk meningkatkan kesiapan igenerations untuk berubah, organisasi harus menciptakannya inisiatif yang dapat mengembangkan self-efficacy, optimisme, harapan dan persistensi individu, sekaligus menciptakan pekerjaan yang bermakna, berdasarkan kompetensi, dan mengakomodasi perubahan individu.

Dukungan organisasi dan manajerial seperti komunikasi yang efektif tentang perubahan, pelatihan, pembinaan dan konseling dapat dianggap sebagai inisiatif yang dapat meningkatkan kesiapan individu untuk berubah. Keterlibatan karyawan dalam proses pengelolaan perubahan juga diyakini dapat meningkatkan makna serta keyakinan diri dan dengan demikian dapat meningkatkan kesiapan individu untuk berubah. 


\section{Rekomendasi Penelitian Selanjutnya}

Ada beberapa keterbatasan dalam penelitian ini yang menjadi rekomendasi bagi penelitian selanjutnya. Pertama, penelitian ini hanya mencakup dua variabel sebagai prediktor. Berdasarkan hal tersebut, untuk penelitian lebih lanjut mengenai kesiapan individu untuk berubah, beberapa lainnya variabel seperti kepemimpinan, dukungan manajerial, hubungan kerja yang positif, budaya organisasi, dan sebagainya dapat disertakan. Kedua, penelitian ini dilakukan dengan total responden $\mathrm{N}=170$ dan menggunakan metode purposive sampling. Untuk penelitian lebih lanjut itu disarankan untuk mengambil sampel yang lebih besar dan menggunakan metode pengambilan sampel lainnya. Ketiga, penelitian lebih lanjut perlu memperhatikan jenis perusahaan yang akan diteliti, karena beda perusahaan mungkin akan memberikan hasil yang berbeda.

\section{DAFTAR PUSTAKA}

Armenakis A.A., \& Bedeian, A.G.,'Organizational change: A review of theory and research in the 1990s", Journal of Management, 1976, Vol.25 No.3, pp. 293-315.

Armenakis A.A., \& Harris, S.G.,"Crafting a change message to create transformational readiness", Journal of Organizational Change Management, 2002, Vol. 15 No.2, pp.169-183.

Armenakis, A.A., Harris, S.G., \& Mossholder, K.W., "Creating readiness for organizational change”, .Human Relations, 1993, Vol. 46 No.6, pp. 681-703

Andrea, B., Gabriella, H., \& Tímea, J. (2016). Y and Z Generations at Workplaces. Journal of Competitiveness, 8(3), 90-106. https://doi.org/10.7441/joc.2016.03.06

Crampton, S. M., \& Hodge, J. W. (2007). Generations in the workplace: Understanding Age Diversity. The Business Review, Cambridge, 9(1), 1622.Retrievedfromhttp://search.proquest.com/docview/197299677?ac countid $=138$

Bandura, A., .Self-efficacy: The exercise of control.1997, New York: Freeman. Bernreth, J. "Expanding our understanding of the change message", .Human Resource Development Review, 2004, Vol. 3 No. 1, pp. 36-52

Bovey, W.H., \& Hede, A., "Resistance to organizational change: The role of defense mechanisms", Journal of Managerial Psychology, 2001, Vol.16, No.7/8, pp.534

Bowen D. E., Ledford, G. E., \& Nathan, B. R. (1991). Hiring for the organization, not the job. Academy of Management Executive, 5(4), 35-49.

Crampton, S. M., \& Hodge, J. W. (2007). Generations in the workplace: Understanding Age Diversity. The Business Review, Cambridge, 9(1), 1622.http://search.proquest.com/docview/197299677?accountid=1382 
Cummings, T. G. and Huse, E. F. (1989). Organization Development and Change, 4th edition. St Paul,MN: West Publishing.

Cummings \& Worley, .Essential of organizational change, 2001, Madison, WI: Thomson South-Western.

Dirks, K.T., Cummings, L.L., \& Pierce, J.L., "Psychological ownership in organization: Condition in which individual promote or resist to change", In R.W Woodman, \& W.A Pasmore (Eds), Research in organizational change and development, 1996, pp.1-23, Greenwich, CT: JAI Press.

Donald, P.M. and Sanjay, K.P. 2007. the Ties that Blind: Social Networks PersonOrganization Fit and Turnover Intention,SSRN, New York, USA.

Eby, L.T., Adams, D.M., Adams, D.M., Russel, J.E., \& Gaby, S.H., "Perceptions of organizational readiness for change: Factor related to employee reactions to the implementation of team-based selling", Human Relations, 2000, Vol.53, No.3,pp.419-428

Fachruddin, D.F. \& Mangundjaya, W., "The impact of workplace well-being and Psychological Capital to Individual Readiness for Change", Proceedings $4^{\text {th }}$ Asian Psychological Association, Jakarta, 5-7 July, 2012. ISBN 978-602-17678-0-1

Gill, R., “Change management or change leadership?", Journal of Change Management, 2003, Vol.3 No.4, pp.307-321.

Haque, M.M., "A study of the relationship between learning organization and organizational readiness for change". Dissertation, 2008, Graduate School of Education and Psychology, Pepperdine University

Hanpachern C., "The extension of theory of margin: A framework for assessing readiness for change". Unpublished Doctoral Dissertation, 1997, Colorado State University, Fort Collins

Herold, D.M., Fedor, D.B., \& Liu, Yi, "The effects of transformational and change leadership employees' commitment to a change: A multilevel study", Journal of Applied Psychology, 2008, Vol.93, No.2, pp.346-357.

Jansen, K.J.,'The emerging dynamics of change: Resistance, readiness, and momentum",Human Resource Planning, 2000, Vol.23, No.2, pp.53-55

Kristof, A. L. 1996. Person-organization fit: an integrative review of its conceptualizations, measurement, and implications. Personnel Psychology49,1-49.

Kupperschmidt, B. R. (2000). Multigeneration employees: strategies for effective management. The Health Care Manager, 19(1), 65-76. https://doi.org/10.1097/00126450-200019010-00011

Lam, T., Cho, V., \& Qu, H., "A study of hotel employee behavioral intention toward adaptation of information technology", Hospitality Management, 2007, Vo.26,pp.49-65

Lewin, G. W. (Ed.) (1948a). Resolving Social Conflict. London: Harper \& Row.

Lewin, G. W. (1948b). 'Preface'. In Lewin, G. W. (Ed.), Resolving Social Conflict. London: Harper \&Row.

Levsque, D.A., Prochaska, J.M., \& Prochaska, J.O., "Stages of change and integrated service delivery". Consulting Psychology Journal: Practice \& Research, 1999, Vol.51, No.4, pp.226-241 
Liu, Yi."When change leadership impacts commitment to change and when it doesn't: A multi-dimensional investigation". Dissertation, 2010, Limited publication. George Institute of Technology, USA.

Lizar, A.A., Mangundjaya,W.L.H., Rachmawan.The Role of Psychological Capital and Psychological Empowerment on Individual Readiness for Change. The Journal of Developing Area, 2015. Vol. 49 (5).

Luthans, Youssef \&Avolio. Psychological capital, 2007, Oxford, United Kingdom; Oxford Press University

Madsen, S.R., "Wellness in the workplace: Preparing employees for change", Organizational Development Journal 2003. Vol.21, No.1, pp.46-55

Madsen, S.R, Miller, D., \& John, C.R., "Readiness for organizational change: Do organizational commitment and social relationship in the workplace make a difference?", Human Resource Development Quarterly, 2005, Vol.16, No.2,pp.213

Madsen, S.R., Miller, D., John, C.R., "Influential factors in individual readiness for change", Journal of Business and Management, 2006, Vol.12, No. 2, pp. 93.

Mannheim, K. (1952). The Problem of Generations. Essays on the Sociology of Knowledge, 24(19), 276-322-24.

Mariotti, J., "10 steps to positive change", Industry Week, 1998. Vol.247, No.14, pp.82.

O'Reilly. C. (1989). Corporations, culture and commitment: Motivation and social control in organizations. Califbrnia Management Review, 31, 9-25.

O'Reilly. C., Chatman, J., \& Caldwell, D. (1991). People and organizational culture: A profile comparison approach to assessing personorganization fit. Academy of Management Journal, 34, 487-516.

Palmer, B., Overcoming resistance to change: Quality Progress, 2004, Vol.37, No.4, pp.35.

Pelletiere, V., "Organization self-assessment to determine the readiness and risk for

planned change", Organization Development Journal, 2006, Vol.24, No.4, pp.38

Rafferty, A.E., \& Simmons, R.H., "An examination of the antecedents of the readiness for fine-tuning and corporate transformation changes", Journal of Business and Psychology, 2006, Vol. 20, No. 3, pp.325-350

Robbins, S. Organizational Behavior, 2013, McGraw-Hill Co., USA Stajkovic, A. \& Luthans, F., "Social cognitive theory and self-efficacy: Going beyond traditional motivation and behavioral approaches", Organizational Dynamics, 1998. Vol.26, pp.62-74

Ryder, N. B. (1965). The Cohort as a Concept in the Study of Social Change. American Sociological Review, 30(6), 843-861. https://doi.org/10.2307/2090964

Schein, E. H. (1988). Organizational Psychology, 3rd edition. London: Prentice Hall.

Schein, E.H. "Personal change trough interpersonal relationship", In W.Bennis,

J.,VanMannen, E. Schein, \& F. Steele (Eds.), Essays in Interpersonal Dynamics, 1979, pp.129-162, Homewood, IL: The Dorsey Press 
Self, D.R., "Organizational change, overcoming resistance by creating readiness", Development and Learning in Organizations, 2007, Vol.21, No.5, pp.11-13 Sellingman, M.E.P., Learned Optimism, 1998, New York: Pocket Books.

Singh, Ajay., \& Gupta, Bindu. (2014). Job involvement, organizational commitment, professional commitment, and team commitment (A study of generational diversity)

Snyder, C.R., Irving, L.M. \& Anderson, J.R., "Hope and health", In C.R. Snyder \& D.R. Forsyth (Eds.), Handbook of Social and Clinical Psychology: The Health Perspective, 1991, pp. 285-305. Elmsford, NY: Pergamon Press

Smith, I., "Achieving readiness for organizational change", Library Management, 2005, Vol.26, pp.6/7, pp.408-412

Spreitzer, G.M., "Psychological empowerment in the workplace: Dimensions, measurement and validation", Academy of Management Journal, 1995, Vol.38, pp.1442-1465 Spreitzer, G.M. "Taking stock: A review of more than twenty years of research on empowerment at work", The Handbook of Organizational Behavior, 2007, Cooprer and Barling (Eds.), Sage Publications.

Walker, H.J. \& Armenakis, A.A., \& Bernerth, J.B., "Factors influencing organizational change efforts: An integrative investigation of change content, context, process and individual differences." Journal of Organizational Change, 2007. Vol.20, No.6, pp.761-773

Wermberg, C.R. \& Bannas, J.T., "Predictors and outcomes of openness to changes in a reorganizing workplace", Journal of Applied Psychology, 2000, Vol.85, No.1 pp.132 - 142 